\title{
Thermal analysis of structural nodes - as locations of difficult geometry, using computational methods
}

\author{
Barbara Ksit ${ }^{1}$, Anna Szymczak-Graczyk ${ }^{2}$ \\ ${ }^{1}$ Poznań University of Technology, Piotrowo 5, 60-965 Poznan, Poland \\ ${ }^{2}$ Poznan University of Life Sciences, Piatkowska 94E, 60-649 Poznan, Poland \\ E-mail: 'barbara.ksit@put.poznan.pl (corresponding author)
}

\begin{abstract}
The determination of mutual correlation between thermal and humidity-related parameters at locations with difficult geometry is still a challenge for designers. External partitions operating in adverse environmental conditions must exhibit specific parameters protecting against condensations and destruction, in order to ensure the operation safety of the entire structure. Both the research, as well as construction reality have shown that thermal bridges are the critical locations of buildings. The Investors often interfere with the design process creating hard-to-accept boundary conditions. Lack of knowledge and experience often results in the formation of construction defects and failures.
\end{abstract}

Keywords: thermal bridges, thermal mapping, structural node.

\section{Introduction}

The determination of mutual correlation between thermal and humidity-related parameters at locations with difficult geometry is still a challenge for designers. External partitions operating in adverse environmental conditions must exhibit specific parameters protecting against condensations and destruction, in order to ensure the operation safety of the entire structure (Błaszczyński, Ksit, \& Grzegorczyk, 2018). Both the research, as well as construction reality have shown that thermal bridges are the critical locations of buildings. The Investors often interfere with the design process creating hard-to-accept boundary conditions. Lack of knowledge and experience often results in the formation of construction defects and failures.

\section{Thermal bridges}

Pursuant to standard PN-EN ISO 10211-1 (Geryło, 2005; Polish Committee for Standardisation, 2008), a thermal bridge is a part of the building envelope, where the uniform thermal resistance changes as a result of:

- partial or complete penetration of the envelope by materials with a varying thermal conductivity coefficient;

- changes of the structural thickness;

-difference between the internal and external areas present at the wall-wall, wall-floor, wall-ceiling connections.

The bridges can be of linear or spot nature. The consequence of thermal resistance changes of a penetration within a thermal bridge area is the local increase of the heat flux transferred by penetration through the building envelope resulting in the decrease of penetration inner surface temperature and the simultaneous increase of the outer surface temperature. Recognizing thermal bridges as an independent heat transfer element (heat losses due to penetration) entails the need for their conscious engineering.

The calculations shall be conducted as per standards PN-EN ISO 10211 (Polish Committee for Standardisation, 2008) and PN-EN ISO 14683 (Polish Committee for Standardisation, 2008). In the case of typical solutions, one can also utilize the catalogues of typical bridges. Sample tables for the determination of sample heat coefficient linear values and a table of their approximate values found in standard PN-EN ISO 14683 (Polish Committee for Standardisation, 2008). Non-typical geometric structures shall be analysed individually. 


\section{Non-destructive testing}

Thermal analysis of a building partition is conducted with the use of the basic energy balance equation, which assumes that energy penetrating through a partition to the environment contains two components: convection and radiation components (Kruczek, 2009). The existence of thermal bridges can be easily identified through a thermal image of the external building wall, taken with a radiation detector. Thermal bridges undoubtedly increase energy loss, since the local temperature value at specified location within a building partition is higher. Temperature increase results in the increase of the radiation and convection fluxes, via which the heat "escapes" to the environment. Thermographic analysis of building partitions (Figure 1) provides a wealth of information on the actual technical condition of thermal insulation.

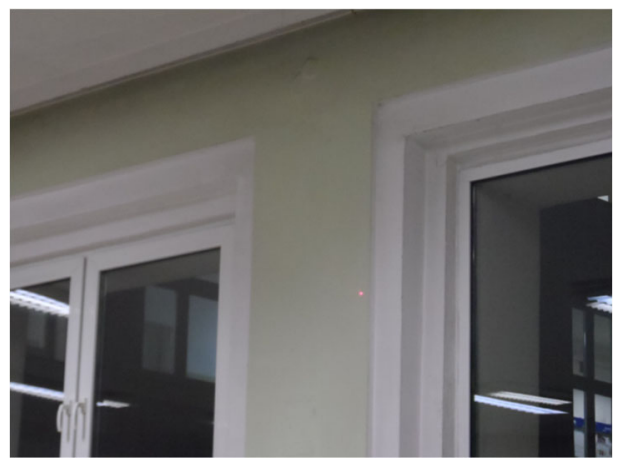

Figure 1. Actual photo of a partition inner surface

The measurements taken on existing objects provide us with a thermogram - a thermal image (Figure 2), which is a heat map of the studied building. If the objective of the testing is to detect deviations from correct thermal conditions and comparing the thermal images is enough to achieve it, using simple and cheap observation cameras is sufficient. Cameras of such type are characterized by a narrow range of measured temperatures and a low-resolution, e.g. $80 \times 80$ px detector. A second group contain measurement thermal imaging cameras with high resolution $(200 \times 150$; $320 \times 240 ; 640 \times 480$ ), also exhibiting a wide range of measured temperatures and a number of functions and solutions improving measurement accuracy (Więcek \& De Mey, 2011; Żurawski, 2010).

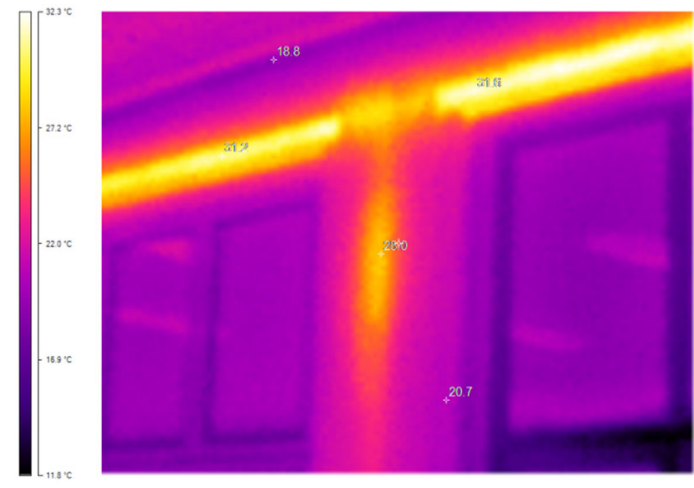

Figure 2. Thermal imaging camera thermogram (flush-mounted wall heating system)

An image of temperature distribution in structural nodes can also be obtained at the engineering stage of the building thermal insulation.

\section{Thermal mapping software}

There are many numerical programs available for a designer in order to model a partition or a critical building location. That software often does not have the option of entering a number of variables, which describe the prevailing actual, environmental (temperature, rain, etc.) conditions or to model a structural geometry solution within the design or existing in reality (there is no option to profile a layer segment in a building partition element). The software database often lacks information on the material data of analysed solutions. The manufacturers also do not facilitate the modelling process, by failing to explicitly declare numerous parameters of construction products. A common issue with modelling is the lack of humidity parameters of the analysed materials. In order to generate the analyses, a designer must utilize the knowledge acquired in the field of heat exchange processes and the technical data of the analysed 
materials. A diligent approach towards the creation of alternative solutions requires experience and interdisciplinary knowledge in order to generate a thermal image of the adopted solutions in the designed partitions. The legislation includes a requirement that a calculated minimum temperature of the outer surface in the area of a $3 \mathrm{D}$ thermal bridge is used as a base to determine the limit relative humidity within a room, which when maintained can be used to assume that this area is protected against the risk of water vapour condensation or fungal development (Geryło, 2005). The correct software modelling of a selected solution results in the following graphs: temperature distribution within the partition and structural nodes, heat flux distribution within thermal bridges, and information on water vapour diffusion.

The Antherm 8.1. software was used for the case analysis. It automatically or semi-automatically creates digitization of details, as well as entire rooms. Results can be presented in 2D, as well as 3D.

\section{Case study}

In order to decrease building erection costs, the developers withdraw from using thermal insulation of garage walls or open basement floors. The considerations covered several variants with moving thermal insulation outside of the construction node, at a depth of $50 \mathrm{~cm}$ and $100 \mathrm{~cm}$. The computational method was developed under the following assumptions:

- uniform air temperature and design temperature distribution (room height under $5 \mathrm{~m}$ );

- air and operating temperature values are the same (well-insulated buildings);

- set conditions (constant temperature);

- fixed properties of building elements as a temperature function.

The analysed model was designed as a structural node of a residential building in the third temperature zone of Poland as per PN-EN 12831:2006 (Polish Committee for Standardisation, 2006). The following was determined for the set structural partition:

Model 1 open garage:

- temperature on layer boundaries $\Theta \mathrm{i} 1=20{ }^{\circ} \mathrm{C}, \Theta i g 1=-20{ }^{\circ} \mathrm{C}, \Theta \mathrm{e}=-20{ }^{\circ} \mathrm{C}$;

- internal humidity $50 \%$;

- external humidity $80 \%$;

Model 2 closed garage:

- temperature on layer boundaries $\Theta_{\mathrm{i} 2}=20^{\circ} \mathrm{C}, \Theta_{\mathrm{ig} 2}=5{ }^{\circ} \mathrm{C}, \Theta_{\mathrm{e}}=-20{ }^{\circ} \mathrm{C}$;

- internal humidity $50 \%$;

- external humidity $80 \%$;

The shape of the node in question in shown in Figure 1. External wall structure was designed of the following layers:

$-2 \mathrm{~cm}$ cement-lime plaster;

$-24 \mathrm{~cm}$ silicate wall;

$-18 \mathrm{~cm}$ mineral wool with $\lambda=0.34 \mathrm{~W} /(\mathrm{m} \cdot \mathrm{K})$;

-wind insulation;

- system sub-structure;

$-20 \mathrm{~mm}$ air gap;

- facade-suspended $12 \mathrm{~mm}$ Corian Glacier white.

The designer assumed unheated garage ceiling insulation with $10 \mathrm{~cm}$ thick lamella wool from the garage side and $24 \mathrm{~cm}$ lamella wool with an additional $5 \mathrm{~cm}$ acoustic polysterene layer on the reinforced concrete ceiling. In order to protect the node, lamella wool strips were fixed on the internal side of the garage wall, and $5 \mathrm{~cm}$ thick polysterene strips on the external side (Figure 3).

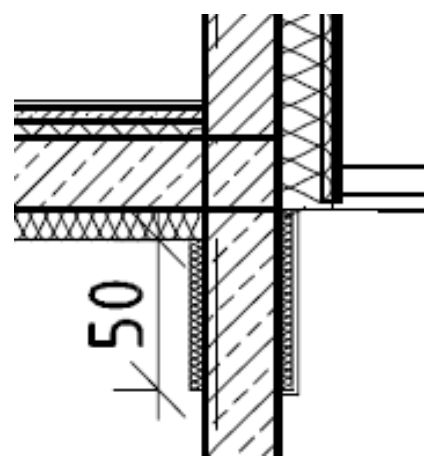

Figure 3. Structural node adopted for the analysis 
The standard PN-EN ISO 13788 (Polish Committee for Standardisation, 2012) sets out a method for calculating the minimum inner surface temperature of a construction component or building element, below which it is possible for mycological changes to develop, under a set temperature and humidity of ambient air. In order to avoid mould growth, the air relative humidity by the surface of an external partition shall not exceed a value of $80 \%$, pursuant to the values stipulated in the Act on Technical Conditions (Technical Conditions, 2015), which is why the analysis adopted the given value as maximum. The partitions were designed as per the requirements set out in the technical conditions to be satisfied by buildings and their locations, according to a Regulation by the Minister of Infrastructure Technical Conditions (2015) regarding the maximum values of the penetration coefficient:

- external wall $\mathrm{U}=0.175 \mathrm{~W} /\left(\mathrm{m}^{2} \mathrm{~K}\right)<\mathrm{U} \max =0.23 \mathrm{~W} /\left(\mathrm{m}^{2} \mathrm{~K}\right)$ at $\mathrm{t}_{\mathrm{i}} \geqslant 16^{\circ} \mathrm{C}$

- floors over unheated rooms $\mathrm{U}=0.223 \mathrm{~W} /\left(\mathrm{m}^{2} \mathrm{~K}\right)<\mathrm{U} \max =0.25 \mathrm{~W} /\left(\mathrm{m}^{2} \mathrm{~K}\right)$ at $\mathrm{t}_{\mathrm{i}} \geqslant 16{ }^{\circ} \mathrm{C}$

Table 1. Values of critical temperatures

\begin{tabular}{|c|c|c|c|c|c|c|c|}
\hline & $\begin{array}{l}\text { Model } 1 \\
\Theta_{\mathrm{i} 1}=20^{\circ} \mathrm{C}\end{array}$ & $\begin{array}{l}\text { Model } 1 \\
\Theta_{\text {igl } 1}=-20^{\circ} \mathrm{C}\end{array}$ & $\begin{array}{l}\text { Model } 1 \\
\text { wall/band }\end{array}$ & $\begin{array}{l}\text { Model } 2 \\
\Theta_{\mathrm{i} 2}=20^{\circ} \mathrm{C}\end{array}$ & \multicolumn{2}{|c|}{$\begin{array}{l}\text { Model } 2 \\
\Theta_{\mathrm{ig} 2}=5{ }^{\circ} \mathrm{C}\end{array}$} & $\begin{array}{l}\text { Model } 2 \\
\text { wall/band }\end{array}$ \\
\hline$\Theta \mathrm{si}_{\mathrm{i}}$ & $9.28^{\circ} \mathrm{C}$ & $-18.69^{\circ} \mathrm{C}$ & $-18.06^{\circ} \mathrm{C}$ & $11.12^{\circ} \mathrm{C}$ & \multicolumn{2}{|c|}{$-4.38^{\circ} \mathrm{C}$} & $-10^{\circ} \mathrm{C}$ \\
\hline$\Psi$ & \multicolumn{3}{|c|}{0.190} & \multicolumn{4}{|c|}{0.119} \\
\hline$f_{\text {Rsi }}$ & \multicolumn{2}{|c|}{$\begin{array}{c}0.73 \\
\left(\Theta_{\mathrm{i} 1}=20^{\circ} \mathrm{C}\right)\end{array}$} & $\begin{array}{c}0.608 \\
\text { (corner garage ceiling) }\end{array}$ & \multicolumn{2}{|c|}{$\begin{array}{c}0.78 \\
\left(\text { dla } \Theta_{\mathrm{i} 2}=20^{\circ} \mathrm{C}\right)\end{array}$} & \multicolumn{2}{|c|}{\begin{tabular}{|l|}
0.624 \\
(corner garage ceiling)
\end{tabular}} \\
\hline$f_{\text {Rsimax }} A$ & \multicolumn{3}{|c|}{0.78} & $\Delta \mathrm{p}[\mathrm{Pa}] \mathrm{A}$ & \multicolumn{3}{|r|}{1080} \\
\hline$f_{\text {Rsimax }} B$ & \multicolumn{3}{|c|}{0.929} & $\Delta \mathrm{p}[\mathrm{Pa}] \mathrm{B}$ & \multicolumn{3}{|r|}{945} \\
\hline
\end{tabular}

A - low-density apartment;

B - high-density apartment;

$\Theta s_{i}-$ inner surface temperature $\left[{ }^{\circ} \mathrm{C}\right]$;

$\mathrm{f}_{\mathrm{Rsimax}}$ - temperature coefficient

$\mathrm{f}_{\mathrm{Rsimax}}$ - data taken from a study for Schöck conducted by ITB (Building Research Institute) regarding the city of Warsaw;

$\Psi$ - linear thermal bridge heat penetration coefficient $[\mathrm{W} /(\mathrm{mK})]$.

Designing partitions to avoid the possibility of developing mold fungi on the internal surface of building partitions boils down to showing that on a yearly scale the maximum computational temperature factor of the internal surface of the $f_{\text {Rsi max }}$ partition will not exceed the real temperature factor $f_{\text {Rsi }}(1)$. Checking the standard condition:

$$
\mathrm{f}_{\text {Rsi }}>\mathrm{f}_{\text {Rsi, max }} \text {. }
$$
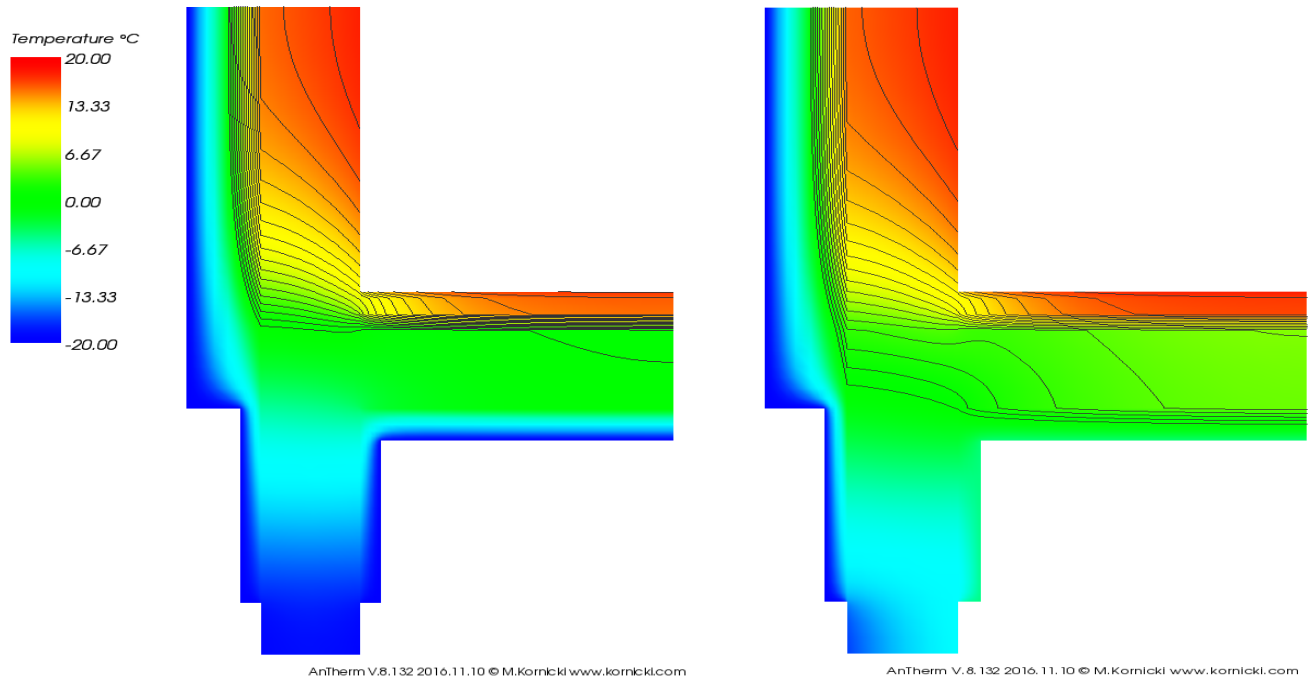

Figure 4. Image of temperature distribution within the structural node - model 1, model 2

The determined temperature coefficient (Table 1) for a critical month is higher than the actual temperature coefficient for the analysed solution. The temperature trajectories for both model 1 (Figure 4), as well as model 2 (Figure 4) showed that the adopted solution was incorrect, and the freezing zone was present throughout the entire node. Shifting thermal insulation to a depth of $50 \mathrm{~cm}$ will not protect the node against destruction. There is a possibility of mycological changes. Shifting thermal insulation onto contact elements will not protect the node against operation in extreme conditions. The contact location is chilled in both considered variants. The dew point, at a relative air humidity of $50 \%$ and a temperature of $+20^{\circ} \mathrm{C}$ is $\mathbf{t}_{\mathbf{s}}=\mathbf{9 . 3}{ }^{\circ} \mathbf{C}$, and for a floor humidity of $60 \%$ is $\mathbf{t}_{\mathbf{s}}=12{ }^{\circ} \mathbf{C}$ in the 
first variant, the temperature of the outer surface of the partition at the critical spot is lower, hence, there is a possibility of condensation. In the second variant, increasing room humidity to $60 \%$ creates also a mycological risk on the node external surface. Shifting the insulation to a depth of $100 \mathbf{c m}$ in the case of elements in contact with the outside environment or operating at low temperatures also does not protect the structural node against the destructive impact of low temperatures. Therefore, this element operates as a conductor transporting low temperatures, which is shown on the isotherms of the node in question.

\section{Conclusions}

Please note that thermal bridges can be a place where biological and physico-chemical degradation processes can take place. A complete construction design shall include models and all data explaining how to correctly solve a specific structural node. The analysis includes correlations between humidity and the penetration coefficient for partition nodes and the study resulted in a conclusion that it was not a linear relationship.

It was shown that the values of the heat penetration coefficient for the analysed partitions was lower than the maximum values given in the Technical Conditions (2015), yet it is not a sufficient criterion to say that a partition was designed correctly. An important aspect in this case is the humidity coefficient, and the internal and external humidity by the analysed partitions.

Calculated temperature coefficient values $\mathrm{f}_{\mathrm{Rsi}}$ as per PN-EN ISO 13788 for a dozen or so cities in Poland (i.a. for Warsaw) are included in a report by ITB No.-00856/15/Z00NF. However, satisfying this requirement (e.g. for a lowdensity apartment the requirement is met) through calculations with a numeric similar method, does not prove a correctly solved issue. Analysing a node with an accurate computational method can help avoid irregularities, which result from using simplified methods. Using nomographs leads to approving solutions, which in previous years were assessed as incorrect, both from the point of view of building physics, as well as the construction art. After a thermal imaging analysis using infrared detectors in the event of executed partitions or numerical software in the event of newly designed partitions, a designer knows where critical (in thermal and humidity terms) areas are located. Please note that not all numerical software enables thorough analyses, hence unacceptable solutions in the designs, which generate destructions and biodegradation of structural elements.

\section{Acknowledgements}

Financial support by the grant $01 / 11 / \mathrm{BSPB} / 0012$ is kindly acknowledged.

\section{References}

Błaszczyński, T., Ksit, B., \& Grzegorczyk, L. (2018). New energy certification of buildings as an element of sustainable construction. University of Technology (in Polish).

Geryło, R. (2005). Heat transfer resistance on the inner surface of the housing in the area of three-dimensional thermal bridges according to PN-EN ISO 10211-1. ITB - Quarterly, 3(135), 31-43 (in Polish).

Kruczek, T. (2009). Determination of radiative ambient temperature during measurements in open air space. Pomiary Automatyka Kontrola, 55(11), 882-885 (in Polish).

Polish Committee for Standardisation. (2006). Heating installations in buildings. The method of calculating the design heat load (PN-EN 12831:2006).

Polish Committee for Standardisation. (2008). Thermal bridges in buildings - Linear heat transfer coefficient - Simplified methods and guide values (PN-EN ISO 14683:2008).

Polish Committee for Standardisation. (2008). Thermal bridges in buildings. Streams of heat and surface temperature. Detailed calculations (PN-EN ISO 10211:2008).

Polish Committee for Standardisation. (2012). Thermal and moisture properties of building components and building elements. The internal surface temperature necessary to avoid critical surface humidity and inter-layer condensation. Calculation methods (PN-EN ISO 13788:2012).

Technical Conditions. (2015). In the matter of technical conditions which should be met by buildings and their location (consolidated text). Dz.U. poz. 1422.

Więcek, B., De Mey, G. (2011). Infrared thermal imaging. Basics and applications. PAK Publishing House, Warsaw. ISBN 97883-926319-7-2 (in Polish).

Żurawski, J. (2010). Evaluation of the quality and correctness of the thermal insulation of the building using the thermovision method. Retrieved from www.cieplej.pl 